\title{
FSES HE 3++ educational standard through the prism of the concept of "Education for sustainable development"
}

\author{
Anna Kovrigina \\ Lomonosov Moscow State University, Leninskie Gory, 1, 119991 Moscow, Russia
}

\begin{abstract}
The emergence of new goals in the educational system, dictated by globalization and technologization of modern society raises the question of the transition to a new pedagogical concept of education for sustainable development. The article proposes a definition of ESD, considers the reflection of the principles of ESD in a single regulatory and methodological complex, consisting of the Federal State Educational Standard of Higher Education $3++$ and exemplary basic educational programs. The author tried to correlate the requirements of the educational standard in linguistics with current professional standards. In the course of the study, proposals are made for the full implementation of the main professional educational programs of a bachelor's degree in "Linguistics" in terms of the concept of ESD. It is concluded that a new educational paradigm is forming now and needs methodological support for the consistent construction of a unified competency model of a graduate at all levels of the educational system, with an emphasis on the formation of personal qualities and activity attitudes necessary for sustainable development of society.
\end{abstract}

\section{Introduction}

The development and implementation of an agreed strategy for sustainable development, which became the key outcome of the UN summit in Rio de Janeiro in 1992, has been announced as a new large-scale project of global significance. On September 25, 2015, the "2030 Agenda for Sustainable Development" was adopted, which contains 17 goals designed to contribute to global prosperity on the path of sustainable development [1]. One of these goals is quality education at all levels in the context of gender equality and equal access to it for people with different opportunities.

To primarily ensure sustainable development in education, and subsequently to transform the national education system into education for sustainable development, the National Education Strategy for Sustainable Development in the Russian Federation was adopted. The precondition for the creation of this document was the 2005 UNECE Strategy for Education for Sustainable Development, designed to motivate participating countries to include in their education systems tools for education, training, assessment and educational control aimed at transforming the end users of educational resources in this way, which will enable them to ensure sustainable development for their countries in the future, meaning 
"ensuring economic viability, justice, social cohesion, environmental protection and sustainable management of natural resources in order to meet the needs of the present without compromising the ability of future generations to meet their needs" [2].

The goals of the presented ECE Strategy for Education for Sustainable Development partially overlap with the goals of the state program of the Russian Federation "Development of Education" for 2018-2025: high-quality and globally competitive education, including according to international research, an increase in the number of employed graduates of secondary vocational education programs, an increase in accessibility education, harmonious personal development and education of socially responsible citizens [3].

In accordance with the provisions of the national ESD strategy in the Russian Federation, education should form interdisciplinary knowledge intended to provide an integrated and systematic approach to solving problems for the country's sustainable development. Also, the ESD doctrine is assumed to be based on the existing "system of classical and engineering environmental education", as well as on the current educational standards, including the "imperatives of sustainable development" [4].

In this regard, it should be noted that the system of classical university education in the Russian Federation is undergoing large-scale restructuring in line with the pan-European modernization of the higher education system to bring it in line with the requirements of the labor market and professional standardization [5-10].

At present, all educational and scientific organizations of the Russian Federation implementing higher education programs must provide education services in accordance with the FSES HE 3++, a framework document of national educational planning prepared in conjunction with the requirements of professional standards. A review of works devoted to the problem of modernization of higher education based on the FSES HE 3++ showed the predominantly critical nature of research on this topic, outlining mainly the difficulties that arise when trying to correlate educational and professional standards $[5,6,7,11,12$, 13].

\section{Objective, Materials, and Methods}

The author of the article sets the goal to firstly define "education for sustainable development" (hereinafter - ESD), outlining the main targets and principles underlying this concept according to the draft document "Key directions for the development of Russian education to achieve the sustainable development goals and objectives in the education system until 2035" and the National ESD Strategy; secondly, to consider the reflection of ESD principles in the text of the new Russian FSES HE 3++ in 45.03.02 "Linguistics"; and, thirdly, to correlate the FSES requirements with the current professional standards designed to determine the conformity of the competencies of a linguist graduate applying for employment in a particular specialty (teacher, translator, specialist in intercultural communication). The analysis also includes the texts of exemplary basic educational programs (EBEP) as recommended for use in the development of educational programs in the relevant areas of training for bachelors. In the course of the study, proposals are made for the full implementation of the basic professional educational programs (BPEP) of the bachelor's degree in "Linguistics" in terms of the ESD concept.

\section{Results and Discussion}

Based on the goals and objectives of education for sustainable development of the country, ESD should be understood as high-quality and affordable education throughout life and at 
all levels (from preschool education to training of highly qualified personnel), brought in line with the requirements of modern society in the material and spiritual spheres. These requirements include primarily practice-centeredness, agility, adaptability of educational programs that form the relevant skills, as well as the need for continuous improvement and updating by employees of their professional knowledge, skills and competencies [1-4]. In addition, given the optimistic context of the development of Russian education in a hightech society strongly influenced by globalization and integration processes, an increase in demand for soft skills is predicted and a decrease in routine work for humans in favor of a robotic workforce (derivative drivers 3 and 4) [14]. Thus, the achievement of the goals and objectives of sustainable development requires specialists capable of professional reflection, self-organization, strong creativity, empathy, multicultural competence and developed high-order cognitive skills: efficiency and flexibility of thinking, the ability to critical analysis, the ability to solve problems, in including attracting knowledge from related disciplines, metasubject competences, etc. This becomes especially relevant in the event of a pessimistic educational scenario arising from the threat of primitivization of the individual in a digital society and the ousting of the human component from the education sector with the replacement of personal presence and interaction with distance learning. The consequence of this development of events is a natural decrease in the ability to critically analyze information, assertiveness in communication, simplification of intellectual activity, as well as a deterioration in communication skills in general.

The search for ways to improve the quality of education and the professional level of graduates leads to a constant update of higher education programs, designed to bring the content of education in line with an external order - the needs of the labor market, the requirements of employers. In light of the threat of educational standards lagging behind scientific and technological progress declared in the draft document "Key directions..." [14], it should be noted that the new FSES HE 3++ tried to reduce the gap between the real needs of society and employers and the results of education in the form of competencies formed among graduates.

Analyzing the integrative characteristics of the results of the development of BPEP in the form of "professional competence" presented in the text of the Federal State Educational Standards, we primarily note the traditional terminological diversity that arises in conditions of insufficient elaboration of regulatory documents. Other official documents give no definition to the concept of "professional competence" introduced by Part 7, Art. 11 FZ-273, and it is unclear whether it can be considered as a synonym for the concept of "competence" to characterize the level of professional training for a certain type of labor activity.

Considering competence as "a program, image, script, frame, rule", I.A. Zimniaia introduces another related term - "competency", understood as "actualization, actual implementation of this potential by a person" [9]. In this interpretation, the concept of "competency" is broader than the concept of "competence", as it characterizes not only the practical (pragmatic) component of training, but includes "motivational, relational, regulatory components along with cognitive knowledge" [9]. Thus, a "competency"-based approach seems to be more correlated with the humanistic values of ESD, defined as the values of the personal, spiritual and moral, and not just the professional development of the graduate.

Trying to bridge the gap between education and spiritual and moral education, the authors of the Federal State Educational Standard include universal and general professional competencies in the results of mastering the bachelor's program, and also give recommendations on the independent formation of a list of professional competencies by educational organizations, the totality of which will give the graduate the opportunity to 
develop professional activities and solve professional tasks, including for ensuring sustainable development.

The new standard certainly gives organizations more freedom in shaping the content and learning outcomes in the form of a list of key professional competencies. On the other hand, it is obvious that the part formed by the participants in educational relations should be minimal to maintain the most uniform competency model of the graduate. For this purpose, it was decided to transfer the task of designing a competency model from the federal educational standard to the level of exemplary basic educational programs (hereinafter referred to as EBEP). We may assert that EBEP is conceived as a kind of templates for developers, which should more disclose the areas (spheres) of professional activity and specific professional tasks, as well as labor functions and qualification requirements of professional standards for the formation of a comprehensive competence model of a graduate, ready for a successful professional activity [15].

Currently, the portal http://fgosvo.ru/ presents EBEP projects in three specialties in "Linguistics": "Theory and practice of intercultural communication", "Theory and methods of teaching foreign languages and cultures", and "Translation and translation studies". They are united by pedagogical and research tasks, their corresponding competencies and indicators of achievement. The difference lies in the need to train translation (for translators) or consulting (for ICC specialists) activities to ensure interlanguage and intercultural communication in various fields, while for teachers this type of tasks and competencies is not provided. In terms of the volume, content, and requirements for learning outcomes, EBEP projects fully correlate with the presented typology of professional tasks for each specialty, thereby forming specific characteristics of the educational program, and this differs from the Federal State Educational Standard, which establishes general requirements for the structure and results of the development of programs.

We may positively characterize the fact that the proposed competency models coincide in terms of the formation of universal, or transversal ("cross-cutting") competencies and social skills, as well as general professional competencies in foreign language proficiency. The specificity of practical activity, which forms the basis of the linguist profession, consists in the intersection of many labor functions: it also includes an expert analysis of linguistic and cultural phenomena, counseling, conflict resolution, interlanguage and intercultural dialogue, reading and drafting scientific, technical, journalistic texts, business documents etc. Consequently, the set of the developed professional competencies should consider the need to work with a large amount of information, as well as constant interaction with people and, accordingly, the need for higher order thinking skills, and flexible skills: critical and innovative thinking, creativity, emotional intelligence, and assertiveness.

The emphasis on the development of cross-cutting competencies and "flexible" skills corresponds to the target setting of ESD and the traditional principles of the fundamental and humanistic orientation of university education in the humanities, and also reflects the versatility and multidimensionality of the professional activity of a linguist, being directly related to the principle of interdisciplinarity declared in the ESD strategy.

Worthy of note is that the list of professional standards included in the register of the Ministry of Labor of the Russian Federation has not been fully elaborated: a draft professional standard "Translation Specialist" has been submitted, but there is still no separate standard for "Linguist" or "Intercultural Communication Specialist". Nevertheless, the list of recommended areas of activity for bachelors of linguistics can be expanded at the expense of other professional standards to increase students' interest in mastering the relevant competencies. In particular, among the standards classified as OKVED 82 "Administrative and economic activities, auxiliary activities to ensure the functioning of the 
organization, activities to provide other support services for business", there are 9 titles suitable for the type of professional activity tasks the graduates can prepare for. We are talking, for example, about the labor functionality of a specialist in organizational and documentation support for managing an organization, a specialist in exhibition activities in trade and industrial exhibitions, a specialist in mediation (mediator), etc., which can be used to detail the competence of a graduate linguist and rapprochement with specific types of activities in demand in the modern labor market [16]. The proposed expansion of the areas of professional activity, characterizing the specifics of the qualifications required for a graduate to pursue a successful career, also correlates with the ESD interdisciplinarity and the need to study problems in their relationship.

To better correlate the results of the educational process with the requirements of the professional community in the interests of sustainable development, we should talk about the creation of an intermediate collegial body, consisting of representatives of business and the university community, whose task would include monitoring the quality of employment of graduates and providing feedback. Third-party management of this issue would allow an independent assessment of the quality of education, the level of satisfaction of graduates with the knowledge and competencies they acquired, as well as difficulties encountered in employment, based on the principles of publicity, transparency, and openness. The monitoring, which is currently being conducted by the Ministry of Education and Science, does not characterize the benefits of the formed competencies in terms of being in demand for employment and further career growth. While properly organized feedback from graduates and employers could bring significant benefits in filling the FSES HE $3++$ in 45.03.02 "Linguistics" with real professional tasks and relevant competencies.

Summarizing the analysis of the new educational standard through the prism of ESD, we note that it does not reflect the global practice of international cooperation. To facilitate the entry of Russia into the single European educational space, to encourage academic and professional mobility, it is required that competencies and, accordingly, higher education diplomas can undergo international homologation and get recognition abroad. This requires harmonizing the competence model of graduates within the framework of a single European space; the first step towards it can be obtaining international accreditation of competencies of a linguistic profile, which will allow graduates to continue their studies and work abroad. The international quality mark means recognition by the European scientific, technical, and professional community of the quality of education and, therefore, support for the international demand for graduates who have received a specialty with the assigned quality mark.

\section{Conclusions}

The studied regulatory and methodological complex, consisting of FSES 3++ and EBEP and updated on the basis of the current professional standards, is designed to determine the basic content of bachelor's educational programs and form the Russian educational space for several years to come. It contains the possibility of implementing the strategy of education for sustainable development, however, the question of translating the de jure principles of ESD into real life remains open, as the regulatory legal documents on education provide no clear methodological guidelines.

According to the above definition of ESD, the fundamental components of education for sustainable development are, firstly, the readiness to permanently continue education and, secondly, the upbringing of certain ideological attitudes in a person. Our country stays on the difficult path of creating a unified system of continuous education aimed at changing a person's self-awareness, forming a responsible attitude towards oneself and towards the surrounding reality based on a whole set of fundamental knowledge, practical skills, moral 
and ethical-axiological attitudes. This complex process is aggravated by the insufficient breadth of coverage of areas of professional activity in the current Register, difficulties in trying to match educational and professional standards, and finally, the lack of full feedback from labor market participants, which together impedes a complete modernization of the Russian education system in the interests of sustainable development, makes it difficult to understand the goals of ESD and support their implementation by the educational community.

\section{References}

1. Transforming our world: The 2030 agenda for sustainable development, https://sdgs.un.org/

2. UNECE strategy for education for sustainable development, https://www.unece.org/

3. State programme: Education development 2018-2025, https://www.garant.ru/

4. National strategy for education for sustainable development in the Russian Federation, https://www.unece.org/

5. A.V. Belotserkovsky, Higher education in Russia, 6, 26 (2015)

6. E.G. Elina, E.N. Kovtun, S.E. Rodionova, Higher education in Russia, 6, 9 (2019)

7. V.S. Senashenko, Higher education in Russia, 6, 31 (2015)

8. E.G. Tareva, Bulletin of Moscow City Pedagogical University: Series: philology, language theory, Language teaching, 2, 75 (2015)

9. I.A. Zimnyaya, Key competencies as an outcome and target basis of the competence approach in education (2004)

10. A.I. Kovrigina, Bulletin of Moscow State University: Series 19. Linguistics and intercultural communication, 4, 46 (2016)

11. I.N. Mishin, Higher education in Russia, 4, 66 (2018)

12. V.A. Prokhorov, Higher education in Russia, 1, 31 (2018)

13. V.S. Senashenko, E.P. Struchkova, RUDN journal of psychology and pedagogics, 16, 451 (2019)

14. Key directions of education development in russia to achieve sustainable development goals in the education system, http://edu2035.firo-nir.ru/

15. A.I. Kovrigina, Collection of articles of the 14th International Conference "Professional education through a foreign language acquisition" (2020)

16. S.A. Pilipenko, A.A. Zhidkov, E.V. Karavaeva, A.V. Serova, Higher education in Russia, 6, 5 (2016) 